Article

\title{
Multiple Goals, Attention Allocation, and the Intention-Achievement Gap in Energy Efficiency Innovation
}

\author{
Tohyun Kim ${ }^{1}{ }^{1(D)}$ and Daegyu Yang ${ }^{2, *(1)}$ \\ 1 SKK Business School, Sungkyunkwan University, Seoul 03063, Korea; tohyunkim@skku.edu \\ 2 School of Management, Kyung Hee University, Seoul 02447, Korea \\ * Correspondence: daegyu@khu.ac.kr; Tel.: +82-2-961-2233
}

Received: 2 August 2020; Accepted: 28 August 2020; Published: 31 August 2020

check for updates

\begin{abstract}
Although improving energy efficiency has many benefits, including not only reducing pollution and climate change but also enhancing productivity and competitiveness, many firms still do not adopt energy efficiency innovation. In this study, we suggest inadequate attention allocation as a barrier to energy efficiency innovation, making firms fall into the intention-achievement gap when they simultaneously pursue multiple innovation-related goals. Due to limits in attention resources, competing innovation goals are likely to divert the firms' focus of attention away from energy efficiency innovation, making them fail to achieve as much as they had initially intended. In addition, we argue that organizational innovation and government dependence will mitigate the attention dispersion effect of multiple goals by enhancing attention capacity and redirecting attention focus, respectively. We empirically examined our hypotheses in the context of Korean manufacturing industries between 2011 and 2013, using the Korean Innovation Survey 2014 data, and found supports for all hypotheses. In particular, we found that even a small increase in the diversity of innovation goals leads to a substantial likelihood of the intention-achievement gap and that organizational innovation and government dependence help to close the gap, but to a limited extent. Finally, theoretical contributions and practical implications are discussed.
\end{abstract}

Keywords: multiple goals; intention-achievement gap; attention allocation; innovation; energy efficiency

\section{Introduction}

Improving energy efficiency reduces the amount of energy use required to produce and provide products and services. Together with renewable energy, energy efficiency is an important measure against pollution and climate change. Indeed, improving energy efficiency is considered one of the most immediate and cheapest tools for achieving energy conservation goals. Thus, many countries and international organizations, including the United Nations (UN) and the International Energy Agency (IEA), have been working together to promote and implement energy efficiency policies. In addition to energy demand reduction and lower greenhouse gas (GHG) emissions, energy efficiency can also provide many other benefits such as economic development, job creation, improvement in human health, and alleviation of poverty [1]. In particular, the IEA notes that benefits for business firms from energy efficiency innovation include enhanced productivity and competitiveness, extended equipment lifetime, lower operation and maintenance costs, improved process and product quality, reduced costs for environmental compliance, and improved work conditions and decreased liability [1].

Nevertheless, research has shown that many firms do not adopt energy efficiency innovation despite these obvious benefits, a phenomenon referred to as the "energy efficiency gap" or the "energy efficiency paradox" (e.g., [2,3]). The paradox points to the question of why profitable and feasible 
energy-saving measures are not adopted by many profit-seeking firms. In order to answer this question, scholars have attempted to identify barriers to energy efficiency (e.g., [4,5]). For example, Cagno et al. [4] identified 27 barriers and proposed a taxonomy classifying these barriers into the following seven categories: technology-related, information-related, economic, behavioral, organizational, competence-related, and awareness. They argued that these barriers variably interfere with the different stages of the decision-making process for energy efficiency innovation: (a) generation of awareness, (b) research of opportunities, and (c) implementation. In this study, we attempt to advance this line of inquiry by focusing particularly on the factors contributing to the intention-achievement gap in energy-efficiency innovation, where firms have the awareness and intention yet eventually fail at implementation.

A strategic intention for innovation originates with an awareness of a problem or need and requires adoption and implementation to achieve innovation outcomes. Although strategic intentions are often construed as the most immediate predictor of innovation achievement, intention and achievement are not always tightly coupled [6]. Indeed, many studies of social psychology have well documented the intention-behavior gap, or the weak relation between intentions and behavioral outcomes [7-9]. For example, Gollwitzer argued that "intentions account for only $20 \%$ to $30 \%$ of the variance in behavior" [8] (p. 493). In the context of environmental innovation at the organization level, Yang and Park [6] noted that, while a strategic intention for environmental innovation results from recognizing the strategic importance of addressing environmental sustainability, setting such an intention does not always guarantee its achievement. Given that firms have limited attention capacity [10], we argue that inadequate attention allocation can prevent them from realizing the strategic intent of energy efficient innovation, especially when they simultaneously pursue multiple competing innovation goals.

Most organizations simultaneously pursue multiple goals rather than focus on a single objective (e.g., [11,12]). For example, many firms are expected to increase short-term profitability, sustain long-term growth, and demonstrate social responsibility. Similarly, as we describe below, our data shows that many firms with an intention to innovate often attempt to concurrently achieve multiple objectives, such as new product development, operational process improvement, and new market entry. However, due to limits in attention resources, the likelihood of achieving an objective tend to decrease as the number of other simultaneously pursued objectives increases [11]. In this paper, we examine how the concurrent pursuit of diverse innovation-related goals may interfere with achieving energy efficiency innovation. Building upon the attention-based view of the firm (ABV) [10], we argue that competing innovation goals are likely to divert the firms' focus of attention away from energy efficiency innovation, which can be mitigated by their organizational innovation and government dependency.

In the following, we develop and examine our hypotheses in the context of Korean manufacturing industries between 2011 and 2013. This study contributes to the energy efficiency literature by investigating the mechanism of attention allocation among multiple innovation goals as a potential barrier contributing to the energy efficiency paradox. In addition, this paper also makes a contribution to research on multiple goals by examining the factors mitigating the negative effects of the concurrent pursuit of multiple goals. Finally, we discuss some practical implications for firm managers and policymakers.

\section{Theory and Hypotheses}

\subsection{Mutiple Innovation Goals, Attention Allocation, and the Intention-Achievement Gap}

To the extent that innovations take long time and large effort under uncertainty, proper attention allocation is crucial for achieving innovation outcomes. In the ABV, attention is defined as "the noticing, encoding, interpreting, and focusing of time and effort" on problems and solutions [10] (p. 189, italics added). Building upon the notion of "bounded rationality", which assumes limitations in the cognitive capacity of decision makers, the ABV argues that firms' actions are determined based on the three interrelated principles: (1) What firms do depends on the problems and solutions on 
which they focus their attention ("Focus of Attention"); (2) what problems and solutions firms focus on depends on the situation in which they find themselves ("Situated Attention"); and (3) what situation firms find themselves in depends on how their rules, resources, and social relationships distribute problems, solutions, and decision-makers across activities, communications, and procedures ("Structural Distribution of Attention") [10,13]. In short, a firm's institutional, economic, and social structure direct its attention focus on selective problems and solutions, which in turn determines its decisions and behavior, including innovation activities.

Struggling to understand the energy efficiency paradox, the literature on energy efficiency has attempted to identify various barriers and drivers of energy efficiency innovation (e.g., [4,5,14]). Nevertheless, the attention allocation problem has not been considered as a source of potential barriers. For example, König noted that "no attempt has been made to apply the ABV to the analysis of decisions related to energy efficiency. This is rather surprising as lack of awareness is frequently identified as a key barrier to energy efficiency measures in industrial organizations" [15] (p. 3). Certainly, generating awareness is crucial as a starting point for energy efficiency innovation [4]. Thus, many policies and initiatives developed by governments and international organizations are aimed at generating awareness of and directing attention to the problems of excessive energy use and the benefits of energy efficiency (e.g., [1]).

However, attentional process involves not only this notion of attention as "noticing" [16] but also "the process of intentional, sustained allocation of cognitive resources to guide problem solving, planning, sensemaking, and decision making" [13] (p. 1288). This process is considered as a form of cognitive search, which can lead to change and innovation in organizations [17]. Therefore, we focus on the problem of inadequate attention allocation in pursuit of multiple innovation goals as an important factor contributing to the intention-achievement gap in energy efficiency innovation.

In dynamically changing technological and competitive environments, firms are facing increasingly more reasons to innovate. Thus, many firms that engage in innovation activities often attempt to accomplish multiple goals simultaneously, such as developing new products, improving production processes, reducing operational costs, and attracting new customers. However, the literature dealing with multiple goals in organizations has well documented the difficulties of concurrent pursuit of diverse goals (e.g., [11,12]). Given limited attention capacity, a firm's addition of a new goal tends to result in the substitution of attention from its previously established goals [11,18]. Hence, Obloj and Sengul [11] argued that the achievement of a goal becomes less likely as the number of other simultaneously pursued goals increases.

Moreover, in competition with other innovation goals, the goal of achieving energy efficiency innovation is likely to end up with a relatively lower priority. When multiple conflicting goals are not aligned, firms tend to prioritize one of them to resolve conflict around the allocation of resources [12]. The behavioral theory of the firm [19] suggested that firms allocate sequential attention to a set of goals prioritized through coalition formation. Or, while one of the goals is selected as primary, other goals may serve as constraints [20]. In any case, we conjecture that energy efficiency innovation will typically receive a lower priority than other more salient innovation goals that are directly related to core business activities [4], such as new product development and new market entry. For these reasons, we hypothesize that firms are less likely to achieve energy efficiency innovation as they have initially intended when they pursue diverse innovation goals simultaneously.

Hypothesis (H1). The more diverse a firm's innovation goals, the more likely there will be a gap between its intention and achievement in energy efficiency innovation.

\subsection{Organizational Innovation and Attention Allocation}

While organizational innovation is sometimes broadly defined as an adoption of any innovation within an organization [21], we use a narrower and more frequently used definition in this study, referring to the implementation of a management process or practice-such as knowledge management 
system, lean production system, Six Sigma program, and total quality management (TQM) -that is new to the organization [22,23]. This definition corresponds to that of "administrative innovation" that occurs in the social system of an organization, as opposed to "technical innovation" that occurs in the technical system [21]. Despite its importance as a source of competitive advantage [24], organizational innovation has been relatively less examined in the literature, compared to product and process innovation $[23,25]$. In fact, prior research has noted that firms tend to engage more in product and process innovation than in organizational innovation [21,24].

We argue, however, that organizational innovation plays an important role in facilitating other types of innovation, including energy efficiency innovation. Regarding the interrelationship between administrative and technical innovations, Damanpour and Evan [21] argued that the adoption of administrative innovations is more likely to trigger the adoption of technical innovations than vice versa because administrative innovations are typically initiated by the top-level managers within the hierarchy and trickle down, while technical innovations tend to originate from the lower-level employees. It means that managers can implement organizational innovations that would motivate and improve the ability of the employees to pursue product and process innovations [21]. Thus, Lam [22] even stated that organizational innovation may be a necessary pre-condition for technological innovation.

In addition, we further suggest that organizational innovation would enhance a firm's attentional capacity by saving its time and effort devoted at management and operational processes, which can then be redirected at achieving other innovation outcomes. Moreover, it may be possible that organizational innovation also reinforces a firm's attentional mindfulness, or the "quality" of organizational attention, which enables overcoming the limits of attention capacity or "quantity" [26]. Such an improvement in the quantity and/or quality of attention would increase the possibility that firms accomplish relatively lower priority goals, such as energy efficiency innovation, even when they pursue multiple innovation goals, either sequentially or simultaneously. Hence, we propose that:

Hypothesis (H2). A firm's organizational innovation will weaken the positive relationship between innovation goal diversity and the intention-achievement gap in energy efficiency innovation.

\subsection{Government Dependence and Attention Allocation}

A firm's interorganizational relationship may also affect its attention allocation. According to resource dependence theory (RDT) [27], organizations are dependent upon other organizations for resources, which generates uncertainty regarding securing stable access to vital resources. Thus, RDT suggests that organizations should manage their dependencies with a variety of tactics-such as search for alternative sources, coalition formation, cooptation, strategic alliances, and acquisition - to reduce the uncertainty. In this sense, RDT implies that a firm's dependence on external resources directs its attention to a specific set of problems (i.e., securing resources) and solutions (i.e., tactics).

In this paper, we focus particularly on the effects of firms' dependence on the government. Ramamurti [28] suggested that, while there are four different types of government dependence, including ownership, regulation, financial (or input), and market (or output) dependence, they do not differ qualitatively in terms of the difficulties they offer to the firms. Indeed, government dependence has been considered as one of the most difficult dependence relationships to manage due to the government's large size, monopolistic power, and ability to change the rules of the game $[29,30]$. Therefore, firms have very few available tactics to manage government dependence, one of them being corporate political activity, such as contributions to political campaigns [31,32].

Given the few tactics available, we argue that government dependence would direct the firms' attention to complying with the government's policy, including energy efficiency improvement. In a study of the U.S. defense contractors, Salancik [33] found that firms' dependence on the government is strongly related to their actions evidencing concern for affirmative action regarding the employment 
of women. Similarly, Aharoni [34] showed that managers of the firms selling a large portion of their goods to the government were more willing to comply with the government's request concerning plant location [27]. Given that governments in many countries are participating in the international efforts to reduce climate change, government-dependent firms with an intention of energy efficiency innovation are likely to devote more time and effort to actually achieving the strategic intent.

Hypothesis (H3). A firm's government dependence will weaken the positive relationship between innovation goal diversity and the intention-achievement gap in energy efficiency innovation.

Figure 1 depicts our research model, in which a firm's innovation goal diversity contributes to its intention-achievement gap in energy efficiency innovation (H1); such a relationship is mitigated by the firm's organizational innovation (H2) and government dependence (H3).

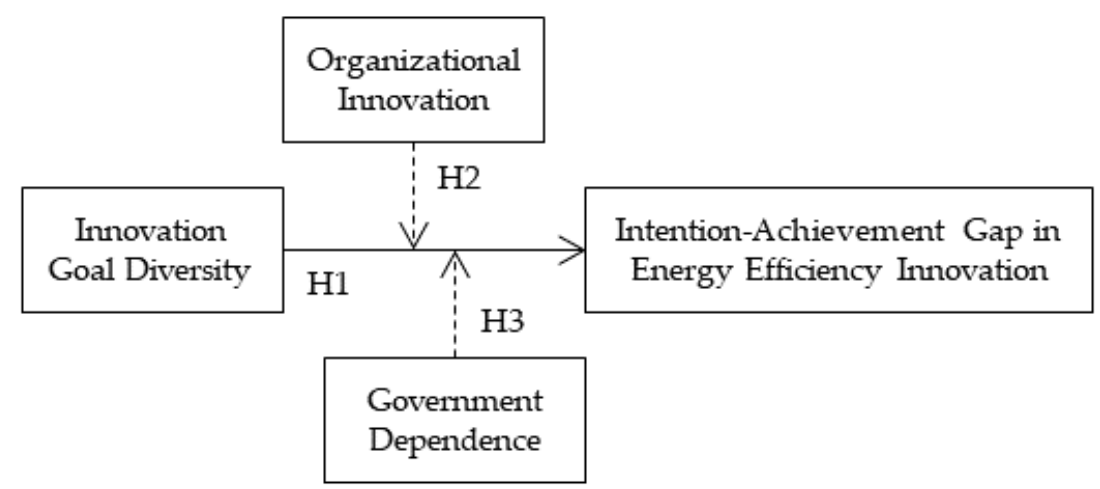

Figure 1. Research Model.

\section{Methods}

\subsection{Data}

To empirically test our hypotheses, we use the "Korean Innovation Survey (KIS): Manufacturing Industry" as the main data source. The survey is biannually carried out by the Science and Technology Policy Institute (STEPI), a representative research institute established and operated by the government of South Korea. In developing the questionnaire items, the KIS follows the Organization for Economic Cooperation and Development's (OECD) Oslo manual that also serves as a set of guidelines to the development of the European Statistical Office's (EUROSTAT) "Community Innovation Survey (CIS)". As such, the KIS design is firmly based on the global standards in terms of validity as well as reliability. Therefore, as an authoritative national survey that monitors companies' innovation-related actions and capabilities in South Korea, the KIS provides highly reliable information that helps the Korean government develop the innovation-related policies. Moreover, because the KIS data is publicly open to independent researchers, a large number of innovation-related studies have used this data (e.g., [6,35-38]).

In 1996, STEPI began to conduct the Korea Innovation Survey on the manufacturing industry as a preliminary test of data collection. After some preliminary implementation tests, the KIS was officially endorsed by Statistics Korea as an official national survey in 2003. The regular data collection was systematically established in 2008, and the KIS has been conducted biannually in the manufacturing industry as well as service industry since then. The microdata is open to the public on request for research purposes, and the most recent data available to date is the KIS 2018. However, despite the availability of more recent KIS data, we decided to use the KIS 2014 for the following reasons: Despite the recency, the KIS 2016 and 2018 do not include the question asking the achievement of innovation objectives, which is very crucial for us to construct the dependent variable in our analysis. That is, the KIS 2014 is actually the most recent data which maintains the achievement 
of innovation objectives along with the intention. Given this, we choose to use the KIS 2014 to test our research hypotheses.

According to the STEPI, the whole population of the KIS 2014 consists of 46,101 manufacturing companies with at least 10 employees. The KIS 2014 selected its sample from the population by using a stratified random sampling strategy in which the industry category and company size were carefully considered in the sampling procedure; the original sample size is 4075 [39]. Within this sample, there are companies that did not answer the questions that we use in the analysis. Therefore, after excluding such missing cases, our final sample includes 1144 firms.

\subsection{Measurements}

\subsubsection{Dependent Variable}

As we discuss in Section 2.2, the intention-achievement gap refers to the case in which firms have the intention of energy efficiency innovation but fail to achieve the implementation to an intended degree. To construct the variable, we use two questions included in the KIS 2014: The first question asks, "During the three years 2011 to 2013, how important were each of the following innovation objectives for your activities to develop product or process innovation?" (intention question), and the second question asks, "During the three years 2011 to 2013, how effectively were each of the following innovation objectives for your activities to develop product or process innovation achieved?" (achievement question). These two questions have 10 specific objectives in common, and the respondents are asked to answer to each objective with a scale of "not relevant $(=0)$ ", "low $(=1)$ ", "medium $(=2)$ ", and "high (=3)". Among the 10 specific objectives listed under the questions, we choose to use "Reduce materials and energy cost per unit output" objective, which we believe represents clearly the energy efficiency of our research interest. Based on the responses to the energy efficiency innovation objective, we regard it as an occurrence of the intention-achievement gap when the respondents give a lower score to the achievement question than to the intention question. For example, if a company answers "medium" to the intention question and "low" to the achievement question, it is regarded that the intention-achievement gap happens. In sum, the variable of intention-achievement gap is constructed as a binary variable that is coded 1 when the intention-achievement gap occurs, otherwise 0 , which enables comparison between firms. In our final sample, 175 companies (16\%) experienced the intention-achievement gap.

\subsubsection{Independent and Moderating Variables}

To measure the diversity of innovation goals, we use the KIS 2014 question, "How important were each of the following objectives for your activities to develop product or process innovation during the three years 2011 to 2013?" Under this question, 10 different objectives were provided: "Increase range of goods", "Replace outdated products or processes", "Enter new markets or increase market share", "Improve quality of goods", "Improve flexibility for producing goods", "Increase capacity for producing goods", "Reduce labor costs per unit output", "Reduce material and energy cost per unit output", "Reduce environmental impacts", and "Improve health or safety of your employees". The respondent is asked to give an answer to each objective by using a scale of "not relevant $(=0)$ ", "low (=1)", "medium (=2)", and "high (=3)". Among the 10 innovation objectives, we exclude "Reduce materials and energy cost per unit output" in constructing innovation objective diversity measure because it is already used in generating our dependent variable. By using the responses to this question, we construct the innovation goal diversity as follows:

$$
\text { Innovation Goal Diversity }=1-\sum_{i}^{9} p_{i}^{2}=1-\sum_{i}^{9}\left(n_{i} / \mathrm{N}\right)^{2},
$$

where $i$ refers to each innovation objective; $p$ refers to the proportion of the weighted importance of an innovation objective to those of all nine innovation objectives; $n$ refers to the response score 
of an innovation objective; and $N$ refers to the total response score of all nine innovation objectives. The innovation goal diversity variable has it range theoretically from 0 to 1 , and it is interpreted that a company has more diverse innovation goals as the value of the variable becomes close to 1 .

To generate the organizational innovation variable, one of the variables that may moderate the relationship between the innovation goal diversity and the intention-achievement gap, we use the KIS 2014 question, "During the three years 2011 to 2013, did your enterprise introduce new business practices for organizing procedures (i.e., supply chain management, business reengineering, knowledge management, lean production, quality management, etc.)?" The respondents are asked to answer to this question with yes or no, and we consider that a company has introduced organizational innovation when the company answers yes to the question. That is, the organizational innovation variable is constructed as a dummy variable (yes $=1$, no $=0$ ), and 276 companies of our final sample have newly introduced organizational innovation.

To measure government dependence, which we introduce as a crucial moderating variable, we use the KIS 2014 question, "During the three years 2011 to 2013, did your enterprise supply products to the domestic public sectors through procurement contracts? (the domestic public sectors include the government, government-owned companies, government-operating institutions including schools or hospitals, etc.)". This question requires a "yes" or "no" answer; therefore, the variable is also constructed as a dummy variable (yes $=1$, no $=0$ ). 223 companies in our final sample fall into the case of governmental dependence.

\subsubsection{Control Variables}

We control for other factors that may influence the intention-achievement gap in the analysis. First, we include the industry dummies in the analysis. By using Korean Standard Industry Code (KSIC), we include 21 industry dummy variables based on the two-digit KSIC categories. Next, we include the company's age in the analysis to capture the age-related effects. Third, we include a dummy variable indicating whether a company is legally categorized as a large-sized company. Forth, we also control for whether a company is listed on Korean stock markets such as KRX or KOSDAQ where the company stock is publicly exchanged. Fifth, we include the company's size which is measured as the number of employees as of 2013. As the distribution of the number of employees is highly skewed, we use the logarithm-transformed value of this variable in the analysis. Finally, we control for the total amount of the expenditure used for innovation activities as of 2013. This variable is also logarithm-transformed in the analysis to reduce the skewness problems.

\section{Results}

In Table 1, we report the descriptive statistics of the variables included in the analysis. As mentioned earlier in Section 3.2.1, out of 1144 companies in our analysis sample, 175 companies (16\%) failed to achieve the energy efficiency innovation as intended during the observation period from 2011 to 2013. It also indicates that many firms are indeed pursuing diverse innovation goals simultaneously as the mean of the innovation goal diversity is 0.64 , which is much closer to the maximum (0.89) than to the minimum (0).

Table 2 shows the pairwise correlations between the variables included in the analysis. While 21 industry code dummy variables are included in the analysis, the results of pairwise correlation analysis including these industry dummy variables are not reported in Table 2 due to the space limitations. A noteworthy finding from the correlation analysis is that innovation goal diversity is positively corelated with the intention-achievement gap as predicted in Hypothesis (H1). That is, it supports our prediction that the more diverse innovation goals a company pursues, the more likely that the company fails to achieve energy efficiency innovation as planned. 
Table 1. Descriptive Statistics.

\begin{tabular}{lcccc}
\hline Variables & Mean & S.D. & Min. & Max. \\
\hline Intention-achievement gap (dummy) & 0.16 & 0.37 & 0 & 1 \\
Age (in year) & 20.3 & 12.75 & 5 & 91 \\
Large company (dummy) & 0.13 & 0.33 & 0 & 1 \\
Listed company (dummy) & 0.15 & 0.35 & 0 & 1 \\
ln (number of employees) & 4.27 & 1.3 & 2.31 & 8.38 \\
ln (expenditure for innovation) & 5.86 & 1.98 & 0 & 12.76 \\
Innovation goal diversity & 0.64 & 0.3 & 0 & 0.89 \\
Organizational innovation (dummy) & 0.25 & 0.43 & 0 & 1 \\
Government dependence (dummy) & 0.2 & 0.4 & 0 & 1 \\
\hline
\end{tabular}

Notes: $N=1144$; industry dummies are not reported due to the space limitations.

Table 2. Pairwise correlations between variables.

\begin{tabular}{|c|c|c|c|c|c|c|c|c|}
\hline Variables & 1. & 2. & 3. & 4. & 5. & 6. & 7. & 8. \\
\hline 1. Intention-achievement gap (dummy) & - & - & - & - & - & - & - & - \\
\hline 2. Age (in year) & $0.08^{*}$ & - & - & - & - & - & - & - \\
\hline 3. Large company (dummy) & $0.20 *$ & $0.35 *$ & - & - & - & - & - & - \\
\hline 4. Listed company (dummy) & 0.03 & 0.30 * & $0.29 *$ & - & - & - & - & - \\
\hline 5. $\ln$ (Number of employees) & $0.13 *$ & $0.48 *$ & $0.63 *$ & $0.46^{*}$ & - & - & - & - \\
\hline 6. $\ln$ (Expenditure for innovation) & 0.03 & $0.31 *$ & $0.39 *$ & $0.39 *$ & $0.62 *$ & - & - & - \\
\hline 7. Innovation goal diversity & $0.27 *$ & 0.09 * & $0.17 *$ & 0.05 & $0.17 *$ & $0.11 *$ & - & - \\
\hline 8. Organizational innovation (dummy) & $0.23 *$ & $0.09 *$ & 0.19 * & 0.08 * & $0.21 *$ & $0.11 *$ & $0.27 *$ & - \\
\hline 9. Government dependence (dummy) & -0.02 & 0.03 & -0.02 & -0.01 & -0.06 & 0.02 & -0.03 & 0.05 \\
\hline
\end{tabular}

Notes: $N=1144 ;{ }^{*} p<0.05$; industry dummies are not reported due to the space limitations.

As our dependent variable is a binary variable indicating whether or not a company fails to achieve the energy efficiency innovation as intended, the hypotheses are tested using the logistic regression analysis. Table 3 presents the results of logistic regression analyses in which all the proposed effects on the intention-achievement gap are carefully examined. The coefficients of the industry dummies, which we include in the logistic analyses as important control variables, are not reported in the table due to the space limitations. To better understand the results, note that if the coefficient of a variable is positive and significant, it means that the probability of failing to achieve the energy efficiency goal as much as intended increases, as the variable increases.

In Model 1, we analyze the control variables and their effects on the intention-achievement gap. The effect of the large company variable is positive and significant, which indicates that large companies are more likely to have the intention-achievement gap problems in their efforts to enhance energy efficiency. Model 1 also shows that a company allocating more financial resources to innovation is less likely to suffer the intention-achievement gap problems. The effects of these two variables are consistent in all the reported models in Table 3.

To test Hypothesis (H1), we add the innovation goal diversity in Model 2 and find that the effect of the variable is positive and significant, which indicates that Hypothesis (H1) is supported. That is, as a company pursues more diverse innovation goals at the same time, it is more likely that the company faces the intention-achievement gap in its efforts to enhance energy efficiency. This effect is also very consistent in all the subsequent models in which we examine the proposed moderating effects.

In Model 3, we add the organizational innovation variable and its interaction term with the innovation goal diversity to test Hypothesis (H2). The coefficient of the interaction term of the organizational innovation and the innovation goal diversity is negative and significant. It indicates that a company introducing organizational innovation is more likely to handle more effectively the intention-achievement gap problems that may be triggered by its pursuit of diverse innovation goals. Finally, to test Hypothesis (H3), whether government dependence mitigates the intention-achievement gap problems that may be provoked by the innovation goal diversity, we add the government 
dependence dummy variable and its interaction term with innovation goal diversity together in Model 4. As can be seen in Model 4, the interaction term of the government dependence and innovation goal diversity is negative and significant, which supports Hypothesis (H3). This result shows that a company having government dependence through procurement contracts is less likely to suffer the intention-achievement gap problems in its efforts to enhance energy efficiency while it aims at diverse innovation goals.

Table 3. Results of Logistic Regression.

\begin{tabular}{lcccc}
\hline Variables & Model 1 & Model 2 & Model 3 & Model 4 \\
\hline (constant) & $-1.83^{* *}$ & $-7.13^{* *}$ & $-7.94^{* *}$ & $-8.12^{* *}$ \\
& $(0.47)$ & $(0.94)$ & $(1.24)$ & $(1.13)$ \\
Age & -0.00 & 0.00 & 0.00 & 0.00 \\
& $(0.01)$ & $(0.01)$ & $(0.01)$ & $(0.01)$ \\
Large company & $1.20^{* *}$ & $1.00^{* *}$ & $1.00^{* *}$ & $1.00^{* *}$ \\
Listed company & $(0.31)$ & $(0.33)$ & $(0.33)$ & $(0.33)$ \\
& -0.33 & -0.31 & -0.31 & -0.34 \\
ln (Number of employees) & $(0.28)$ & $(0.30)$ & $(0.30)$ & $(0.30)$ \\
& 0.16 & 0.11 & 0.07 & 0.11 \\
ln (Expenditure for innovation) & $(0.11)$ & $(0.11)$ & $(0.12)$ & $(0.12)$ \\
& $-0.11^{*}$ & $-0.15^{*}$ & $-0.15^{*}$ & $-0.15^{*}$ \\
Innovation goal diversity & $(0.06)$ & $(0.06)$ & $(0.06)$ & $(0.06)$ \\
& - & $7.07^{* *}$ & $8.05^{* *}$ & $8.29^{* *}$ \\
Organizational innovation & - & $(1.00)$ & $(1.40)$ & $(1.24)$ \\
Innovation goal diversity $\times$ Organizational innovation & - & - & $3.99^{* *}$ & - \\
& - & - & $(1.51)$ & - \\
Government dependence & - & - & $-4.09 *$ & - \\
Innovation goal diversity $\times$ Government dependence & - & - & $(1.85)$ & - \\
Log-likelihood & - & - & - & $3.16^{*}$ \\
pseudo $R^{2}$ & -447.84 & -387.36 & -379.69 & -385.13 \\
\hline
\end{tabular}

Notes: $N=1144 ;{ }^{*} p<0.05 ;{ }^{* *} p<0.01$; industry code dummies are not reported due to the space limitations.

In Figure 2, we present the visual illustrations of the moderating effects examined in Model 3 and Model 4 to provide better understandings. Figure 2a visually depicts how the introduction of organizational innovation affects the relationship between the innovation goal diversity and the intention-achievement gap. Compared with the solid line (organizational innovation is not introduced), the dashed line (organizational innovation is introduced) is located lower and its slope is less steep, which portrays the moderating effects of organizational innovation. Likewise, Figure $2 b$ depicts how government dependence moderates the positive relationship between the innovation goal diversity and the intention-achievement gap in energy efficiency efforts. The dashed line (government dependence exists) is located lower and its slope is less steep than the solid line (government dependence does not exist), which clearly exhibits support for Hypothesis 3. 


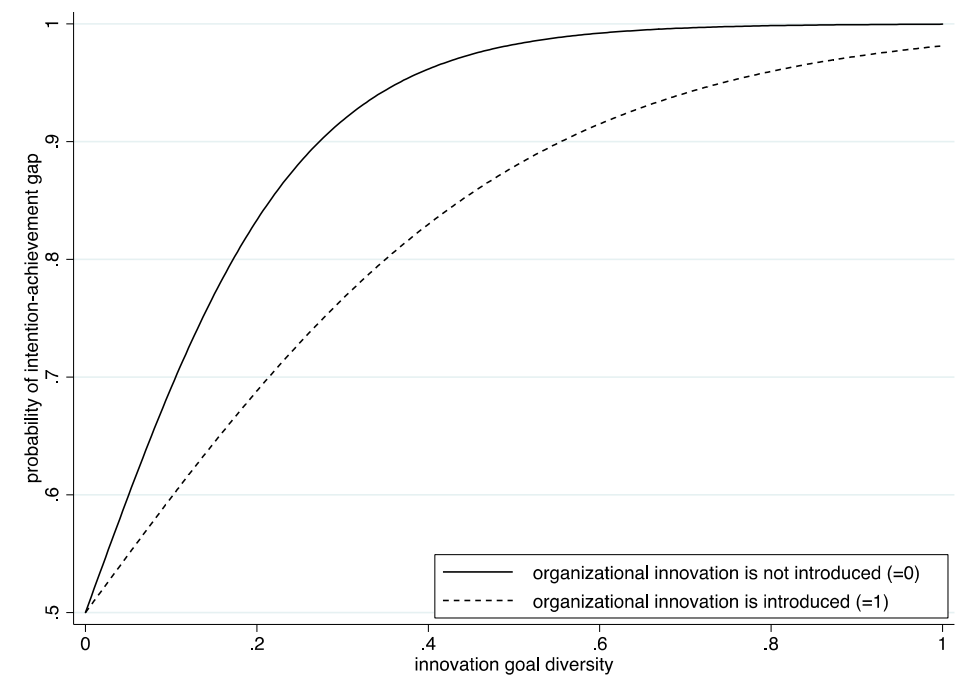

(a)

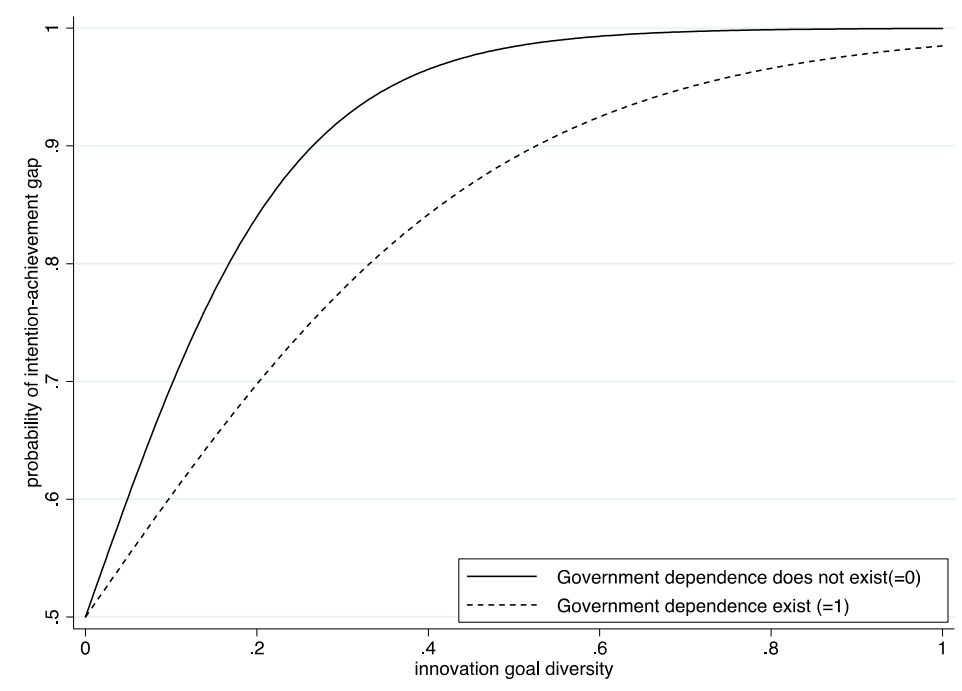

(b)

Figure 2. The moderating effects of (a) organizational innovation and (b) government dependence on the relationship between innovation goal diversity and the probability of the intention-achievement gap in energy efficiency innovation.

\section{Discussion}

Building upon the attention-based view of the firm [10], this paper proposes an attention-based view of the intention-achievement gap in energy efficiency innovation. We argued that a firm's likelihood of failing to achieve energy efficiency innovation as much as it had initially intended tends to increase as the diversity of other innovation-related goals the firm simultaneously pursue increases due to limited attention capacity. Furthermore, we suggested that a firm's organizational innovation and government dependence will mitigate the attention dispersion effect of multiple goals by enhancing its attention capacity and redirecting its attention focus, respectively. We empirically examined our hypotheses in the context of Korean manufacturing industries between 2011 and 2013, using the Korean Innovation Survey 2014 data, and found supports for all three hypotheses. In particular, we found that (a) even a small increase in the diversity of innovation goals leads to a substantial likelihood of 
the intention-achievement gap and that (b) organizational innovation and government dependence help to close the gap but to a limited extent (see Figure 2).

Our findings contribute to the energy efficiency literature by providing a new, partial explanation to the energy efficiency paradox. While many scholars have attempted to identify various barriers to and drivers of energy efficiency innovation in order to understand why firms do not initiate energy efficiency measures despite apparent internal and external benefits (e.g., [4,5,14]), few of them have considered the problem of inadequate attention allocation, especially in the firms pursuing multiple innovation-related goals concurrently. This paper not only suggests this problem as a potential barrier but also provides some possible solutions, showing that organizational innovation and government dependence can indirectly drive energy efficiency innovation by reducing the negative effects of pursuing multiple goals.

Our study also contributes to the literature on organizational goals. This literature has long recognized that most, if not all, firms are pursuing multiple goals simultaneously, which tends to reduce the likelihood that they will accomplish any of the goals [11]. Based upon the ABV, we argued that the pursuit of multiple goals results in the dispersion of limited attention resources, which can be especially detrimental to relatively lower priority goals. Moreover, our findings suggest that organizational innovation may enhance attention capacity and enable concurrent pursuit of multiple goals, while government dependence can redirect a firm's attention towards accomplishing a lower-priority goal that has benefits to the society.

This paper proffers some practical implications as well. In order to overcome the problem of attention dispersion in pursuit of multiple competing goals, managers may want to consider prioritizing groups of related goals and sequentially allocating a proper amount of attention to them. Furthermore, if a firm should achieve a less salient but still important goal, such as energy efficiency, it may be useful to assign the task of accomplishing the goal to a separate team or unit. Above all, if the firm is under continuous pressure to pursue diverse goals concurrently, the managers should implement organizational innovation that can enhance the quantity and quality of its attention resources. Finally, policymakers promoting energy efficiency should understand that many firms fail to achieve energy efficiency innovation even though they have the strategic intent, not because they are unaware of the benefits of energy efficiency. Thus, the policymakers should find ways to encourage the firms more explicitly to allocate more attention resources to energy efficiency innovation, rather than simply generating awareness of the benefits (cf. [1]).

This study has some limitations that deserve future inquiry. Since our empirical analysis is based on the dataset constructed by a survey method, it is subject to some concerns regarding the reliability of responses. More specifically, self-reported responses to the survey questions can be rather subjective than objective and biased towards self-enhancement and social desirability. Although the KIS has been conducted by an authoritative, government-funded research institute following the global standard and thus considered as a reliable data source by prior studies (e.g., [6,35-38]), future studies would benefit from using other research methods and data sources. Another limitation is the generalizability of our findings. Our research context, Korean manufacturing industries between 2011 and 2013, may have some unique institutional, cultural, and economic features, which could have affected the results. Thus, our findings need to be validated in other contexts. We believe and hope that these limitations will be addressed by future research.

Author Contributions: D.Y. provided initial research ideas and analyzed the data. T.K. developed the theoretical arguments. Both authors designed the overall research model and wrote the final manuscript. All authors have read and agreed to the published version of the manuscript.

Funding: The research received no external funding.

Acknowledgments: We would like to thank the anonymous reviewers for their careful reading of our manuscript and their many helpful comments and suggestions.

Conflicts of Interest: The authors declare no conflict of interest. 


\section{References}

1. IEA. Capturing the Multiple Benefits of Energy Efficiency; IEA: Paris, France, 2014.

2. DeCanio, S.J. The efficiency paradox: Bureaucratic and organizational barriers to profitable energy-saving investments. Energy Policy 1998, 26, 441-454. [CrossRef]

3. Jaffe, A.B.; Stavins, R.N. The energy-efficiency gap: What does it mean? Energy Policy 1994, 22, 804-810. [CrossRef]

4. Cagno, E.; Worrell, E.; Trianni, A.; Pugliese, G. A novel approach for barriers to industrial energy efficiency. Renew. Sustain. Energy Rev. 2013, 19, 290-308. [CrossRef]

5. Sorrell, S.; Schleich, J.; Scott, S.; O'Malley, E.; Trace, F.; Boede, U.; Ostertag, K.; Radgen, P. Reducing Barriers to Energy Efficiency in Public and Private Organizations; University of Sussex: Brighton, UK, 2000.

6. Yang, D.; Park, S. Too much is as bad as too little? Sources of the intention-achievement gap in sustainable innovation. Sustainability 2016, 8, 712. [CrossRef]

7. Armitage, C.J.; Conner, M. Efficacy of the theory of planned behavior: A meta-analytic review. Br. J. Soc. Psychol. 2001, 40, 471-499. [CrossRef] [PubMed]

8. Gollwitzer, P.M. Implementation intentions: Strong effects of simple plans. Am. Psychol. 1999, 54, 493-503. [CrossRef]

9. Gollwitzer, P.M.; Sheehan, P. Implementation intentions and goal achievement: A meta-analysis of effects and processes. Adv. Exp. Soc. Psychol. 2006, 38, 69-119.

10. Ocasio, W. Towards an attention-based view of the firm. Strat. Manag. J. 1997, 18, 187-206. [CrossRef]

11. Obloj, T.; Sengul, M. What do multiple objectives really mean for performance? Empirical evidence from the French manufacturing sector. Strat. Manag. J. 2020. forthcoming.

12. Unsworth, K.; Yeo, G.; Beck, J. Multiple goals: A review and derivation of general principles. J. Organ. Behav. 2014, 35, 1064-1078. [CrossRef]

13. Ocasio, W. Attention to attention. Organ. Sci. 2011, 22, 1286-1296. [CrossRef]

14. Trianni, A.; Cagno, E.; Marchesani, F.; Spallina, G. Classification of drivers for industrial energy efficiency and their effect on the barriers affecting the investment decision-making process. Energy Effic. 2017, 10, 199-215. [CrossRef]

15. König, W. Energy efficiency in industrial organizations-A cultural-institutional framework of decision making. Energy Res. Soc. Sci. 2020, 60, 101314. [CrossRef]

16. Corner, P.D.; Kinicki, A.J.; Keats, B.W. Integrating organizational and individual information processing perspectives on choice. Organ. Sci. 1994, 5, 294-308. [CrossRef]

17. Ocasio, W.; Joseph, J. Rise and fall-Or transformation? The evolution of strategic planning at the General Electric Company, 1940-2006. Long Range Plan. 2008, 41, 248-272. [CrossRef]

18. Stevens, R.; Moray, N.; Bruneel, J.; Clarysse, B. Attention allocation to multiple goals: The case of for-profit social enterprises. Strat. Manag. J. 2015, 36, 1006-1016. [CrossRef]

19. Cyert, R.M.; March, J.G. A Behavioral Theory of the Firm; Blackwell Inc.: Englewood Cliffs, NJ, USA, 1963.

20. Hu, S.; Bettis, R.A. Multiple organization goals with feedback from shared technological task environments. Organ. Sci. 2018, 29, 873-889. [CrossRef]

21. Damanpour, F.; Evan, W.M. Organizational innovation and performance: The problem of organizational lag. Adm. Sci. Q. 1984, 29, 392-409. [CrossRef]

22. Lam, A. Organizational Innovation. In The Oxford Handbook of Innovation; Fagerberg, J., Mowery, D., Nelson, R., Eds.; Oxford University Press: Oxford, UK, 2004.

23. Sapprasert, K.; Clausen, T.H. Organizational innovation and its effects. Ind. Corp. Chang. 2012, 21, $1283-1305$. [CrossRef]

24. Hamel, G. The why, what and how of management innovation. Harv. Bus. Rev. 2006, 84, 72-84.

25. Damanpour, F.; Walker, R.M.; Avellaneda, C.N. Combinative effects of innovation types and organizational performance: A longitudinal study of service organizations. J. Manag. Stud. 2009, 46, 650-675. [CrossRef]

26. Weick, K.E.; Sutcliffe, K.M. Mindfulness and the quality of organizational attention. Organ. Sci. 2006, 17, 514-524. [CrossRef]

27. Pfeffer, J.; Salancik, G.R. The External Control of Organizations: A Resource Dependence Perspective; Harper \& Row: New York, NY, USA, 1978. 
28. Ramamurti, R. Strategic planning in government-dependent businesses. Long Range Plan. 1986, $19,62-71$. [CrossRef]

29. Abdurakhmonov, M.; Ridge, J.W.; Hill, A.D. Unpacking firm external dependence: How government contract dependence affects firm investments and market performance. Acad. Manag. J. 2020. forthcoming. [CrossRef]

30. Aharoni, Y.; Maimon, Z.; Segev, E. Interrelationships between environmental dependencies: A basis for tradeoffs to increase autonomy. Strat. Manag. J. 1981, 2, 197-208. [CrossRef]

31. Hillman, A.J.; Keim, G.D.; Schuler, D. Corporate political activity: A review and research agenda. J. Manag. 2004, 30, 837-857. [CrossRef]

32. Sutton, T.; Devine, R.A.; Lamont, B.T.; Holmes, R.M., Jr. Resource dependence, uncertainty, and the allocation of corporate political activity across multiple jurisdictions. Acad. Manag. J. 2020. forthcoming. [CrossRef]

33. Salancik, G.R. Interorganizational dependence and responsiveness to affirmative action: The case of women and defense contractors. Acad. Manag. J. 1979, 22, 375-394. [CrossRef]

34. Aharoni, Y. The Israeli Manager; Israeli Institute of Business Research, Tel Aviv University: Tel Aviv-Yafo, Israel, 1971.

35. Choi, H.; Yi, D. Environmental innovation inertia: Analyzing the business circumstances for environmental process and product innovations. Bus. Strat. Environ. 2018, 1, 1-12. [CrossRef]

36. Chun, D.; Chun, Y.; Woo, C.; See, H.; Ko, H. Labor Union Effects on Innovation and Commercialization Productivity: An Integrated Propensity Score Matching and Two-Stage Data Envelopment Analysis. Sustainability 2015, 7, 5120-5138. [CrossRef]

37. Seo, H.; Chung, Y.; Woo, C.; Chun, D.; Jang, S.S. SME's appropriability regime for sustainable development-The role of absorptive capacity and inventive capacity. Sustainability 2016, 8, 665. [CrossRef]

38. Yang, D. What should SMEs consider to introduce environmentally innovative products to market? Sustainability 2019, 11, 1117. [CrossRef]

39. Korea Innovation Survey. Available online: http://www.stepi.re.kr/kis/index.do (accessed on 30 July 2020).

(C) 2020 by the authors. Licensee MDPI, Basel, Switzerland. This article is an open access article distributed under the terms and conditions of the Creative Commons Attribution (CC BY) license (http://creativecommons.org/licenses/by/4.0/). 